\title{
Cefodizime Sodium
}

National Cancer Institute

\section{Source}

National Cancer Institute. Cefodizime Sodium. NCI Thesaurus. Code C98225.

The sodium salt form of cefodizime, a third-generation, aminothiazolyl cephalosporin for parenteral use. Cefodizime has broad-spectrum activity and is stable to most betalactamases. 